\title{
PENGARUH COGNITIVE BEHAVIOUR THERAPY (CBT) TERHADAP PENINGKATAN BODY IMAGE SATISFACTION PADA \\ REMAJA
}

\section{Nia Agustiningsih, Qori Fanani ${ }^{1}$}

${ }^{1}$ Sekolah Tinggi Ilmu Kesehatan Kepanjen

Corresponding author:

Nia Agustiningsih

Sekolah Tinggi Ilmu Kesehatan Kepanjen

Email: Nia_agustiningsih@yahoo.com

\section{Article Info:}

Dikirim: 13 September 2019

Ditinjau: 14 September 2019

Diterima: 26 September 2019

DOI:

https://doi.org/10.33475/jikmh.v8i2.207

\section{Abstract}

The existence of wrong thoughts about body image will cause a teenager to do maladaptive behavior to improve body image satisfaction. In this regard, adolescents who have decreased body image satisfaction can be given cognitive behavioral therapy (CBT). The purpose of this study was to determine body image satisfaction before and after being given cognitive behavioral therapy (CBT). This research is a queasy experimental pre-post test. The population in this study were all teenagers at SMK Muhammadiyah 5 Kepanjen with simple random sampling technique with a sample size of 50 people. The stages of the research in this study consisted of the preparation phase, the implementation stage which consisted of pre-test, cognitive intervention behavioral therapy (CBT) intervention and post test. The instrument used for pre-test and post-test was a questionnaire about body image satisfaction. The study was conducted at SMK 5 Muhammadiyah Kepanjen in May 2019. Data analysis was performed using paired t-tests. Research data are presented in the form of frequency distribution tables and narratives. The results showed that the average body image satisfaction (pre test) was 93.7 and body image satisfaction (post test) was 108.74 with an average difference of 15.04. The results of data analysis found that the p-value of 0,000<0.05, which means that there are significant differences in body image satisfaction between before and after given cognitive behavioral therapy $(C B T)$. From these results that cognitive behavior therapy (CBT) can be used as an alternative to the provision of psychotherapy in adolescents who experience a decrease in body image satisfaction

\section{Keyword: body image; cognitive behavior therapy (CBT); psychotherapy}

\begin{abstract}
Abstrak
Adanya pemikiran yang salah terhadap body image akan menyebabkan seorang remaja melakukan perilaku yang maladaptif untuk meningkatkan body image satisfaction. Berkaitan dengan hal tersebut maka remaja yang mengalami penurunan body image satisfaction bisa diberikan cognitive behaviour therapy (CBT). Tujuan dalam penelitian ini adalah untuk mengetahui body image satisfaction sebelum dan setelah diberikan cognitive behaviour therapy (CBT). Penelitian ini merupakan merupakan Quasy Experimental Pre - Post Test. Populasi dalam penelitian ini adalah seluruh remaja di SMK Muhammadiyah 5 Kepanjen dengan tehnik pengambilan sampel simple random sampling dengan besar sampel 50 orang. Tahapan penelitian dalam penelitian ini adalah terdiri dari tahap persiapan, tahap pelaksanaan yang terdiri dari pre test, pemberian intervensi cognitive behaviour therapy (CBT) dan post test. Instrument yang digunakan untuk pre test dan post test adalah kuesioner tentang body image satisfaction. Penelitian dilakukan di SMK 5 Muhammadiyah Kepanjen pada bulan Mei 2019. Analisis data dilakukan dengan menggunakan paired $t$-test. Data hasil penelitian disajikan dalam bentuk tabel distribusi frekuensi dan narasi. Hasil penelitian menunjukkan bahwa rata - rata body image satisfaction (pre test) yaitu 93,7 dan body image satisfaction (post test) yaitu 108,74 dengan rata - rata selisih adalah 15,04. Hasil analisis data didapatkan bahwa nilai $p$-value $0,000<0,05$ yang artinya ada perbedaan bermakna pada body image satisfaction antara sebelum dan sesudah diberikan cognitive behaviour therapy (CBT). Dari hasil tersebut bahwa cognitive behaviour therapy (CBT) bisa digunakan sebagai alternatif pemberian psikoterapi pada remaja yang mengalami penurunan terhadap body image satisfaction.
\end{abstract}

Kata Kunci: body image, cognitive behavior therapy (CBT); psychotherapy 


\section{PENDAHULUAN}

Masa remaja adalah periode perkembangan yang sering dikaitkan dengan masalah body image. Masa remaja merupakan masa transisi yang melibatkan aspek sosial, kognitif, fisik, psikologis dan emosional yang terjadi karena tahap pertumbuhan dan perkembangan. Berdasarkan studi pendahuluan diketahuan bahwa dari 10 remaja menyampaikan jika merasa hidungnya kurangnya mancung, kulitnya kurang putih, tinggi badannya pendek, tubuhnya terlalu gemuk dan tubuhnya terlalu kurus. Beberapa perkembangan yang bisa diamati pada masa remaja adalah perubahan tinggi badan, berat badan, seksual sekunder yang merupakan bagian dari masa pubertas (Murray et al, 2011; Lipowski et al, 2016). Adanya perubahan - perubahan tersebut akan menyebabkan remaja mengalami perubahan body image. Dengan adanya perkembangan kognitif pada masa remaja maka remaja mulai bisa berfikir bahwa apa yang ada dalam diri remaja bisa dievaluasi oleh orang lain. Hal ini merupakan hal yang normal selama masa perkembangan remaja namun juga merupakan tantangan bagi remaja untuk bisa menerima atau menyesuaikan diri akibat perubahan body image . Body image merupakan isu yang utama yang muncul pada masa remaja. Murray et al (2011) menjelaskan bahwa body image adalah hasil dari penilaian secara menyeluruh pada tubuh yang meliputi, sikap, kognitif, perilaku, estetika, sensasi, fungsi, kebugaran dan kesehatan. Penerimaan body image pada remaja berkaitan dengan pengalaman remaja dalam interaksi sehari - hari dengan teman sebaya, penerimaan dan perhatian teman sebaya. Adanya evaluasi negatif dari teman sebaya berkaitan dengan body image akan menyebabkan remaja memiliki pemikiran yang negatif terhadap body image sehingga akan menyebabkan penurunan Body Image Satisfaction. Body Image Satisfaction yang rendah akan bisa menyebabkan gangguan dan perubahan perilaku seperti depresi, dorongan untuk kurus, gangguan makan, dysmorphia tubuh, harga diri rendah, dan perilaku yang mengorbankan kesehatan seperti diet dan penggunaan steroid (Jones and Smolak, 2011).

Adanya pemikiran yang salah terhadap body image akan menyebabkan seorang remaja melakukan perilaku yang maladaptif untuk meningkatkan Body Image Satisfaction. Berkaitan dengan hal tersebut maka remaja yang mengalami penurunan Body Image Satisfaction bisa diberikan Cognitive Behaviour Therapy (CBT) (Talen and Mann, 2009). CBT adalah salah satu bentuk psikoterapi yang merubah pikiran negatif menjadi postif sehingga akan perilaku maladaptif yang muncul akibat pola pikir yang salah bisa berubah menjadi perilaku yang adaptif. Dengan adanya terapi ini diharapkan Body Image Satisfaction pada remaja meningkat.

\section{METODE}

Penelitian ini merupakan penelitian Quasy Experimental Pre Post Test. Populasi dalam penelitian ini adalah seluruh remaja di SMK Muhammadiyah 5 Kepanjen. Pengambilan sampel dilakukan dengan tehnik simple random sampling dengan kriteria penelitian yang sudah ditentukan oleh peneliti yaitu krieria inklusi meliputi remaja (siswa) yang bersedia menjadi responden dan sedang tidak sakit, sedangkan kriteria ekslusi dalam penelitian ini adalah remaja (siswa) yang sedang tidak hadir dalam penelitian atau sedang melaksanakan kegiatan sekolah yang tidak bisa diganggu. Penelitian dilakukan pada bulan Mei 2019 di SMK Muhammadiyah 5 Kepanjen. Kuesioner yang digunakan untuk mengetahui body image satisfaction diadaptasi dari Body image satisfaction questionnaire. Data dianalisis dengan menggunakan paired t-test dan disajikan dalam bentuk tabel distribusi frekuensi dan narasi. Dalam penelitian ini 
memperhatikan prinsip etika penelitian yaitu dengan memberikan penjelasan tujuan penelitian untuk ikut berpartisipasi melalui Informed consent, menyamarkan identitas responden (Anonymity), setiap responden diperlakukan secara adil (justice), penelitian memberikan manfaat yang baik pada responden (beneficience).

\section{HASIL}

\section{Analisis Univariat}

\section{a. Karakteristik Responden}

Karakteristik responden dalam penelitian ini yaitu meliputi dan berusia 17 tahun berjumlah 23 orang $(46 \%)$.

b. Skor Body Image Satisfaction sebelum diberikan Cognitive Behaviour Therapy (CBT)

Rata - rata skor Body Image Satisfaction pada remaja sebelum diberikan Cognitive Behaviour Therapy (CBT) adalah 93,7 dengan standar deviasi 10,5.

c. Skor Body Image Satisfaction sesudah diberikan Cognitive Behaviour Therapy (CBT)

Rata - rata skor Body Image Satisfaction pada remaja sesudah diberikan Cognitive Behaviour Therapy (CBT) adalah 108,74 dengan standar deviasi 9,8. Rata - rata peningkatan body image setelah diberikan Cognitive Behaviour Therapy (CBT) adalah 15,04.

\section{Analisis Bivariat}

Berdasarkan hasil analisis data dengan menggunakan paired $t$ test bahwa p-value 0,000 yang artinya ada perbedaan yang signifikan pada rata - rata Skor Body Image Satisfaction antara sebelum dan sesudah diberikan Cognitive Behaviour Therapy (CBT).

\section{PEMBAHASAN}

\section{Karakteristik Responden}

a. Usia

Tabel 1 Karakteristik Responden

\begin{tabular}{llcc}
\hline Variabel & Kategori & \multicolumn{2}{c}{ Jumlah } \\
\cline { 3 - 4 } & & $\mathbf{N}$ & $\mathbf{\%}$ \\
\hline Jenis & Laki - Laki & 9 & 18 \\
Kelamin & Perempuan & 41 & 82 \\
& Total & $\mathbf{5 0}$ & $\mathbf{1 0 0 \%}$ \\
\hline Usia & 15 tahun & 4 & 8 \\
& 16 tahun & 19 & 38 \\
& 17 tahun & 23 & 46 \\
& 18 tahun & 3 & 6 \\
& 19 tahun & 1 & 2 \\
& Total & $\mathbf{5 0}$ & $\mathbf{1 0 0 \%}$ \\
\hline
\end{tabular}

Berdasarkan Tabel 1 menunjukkan bahwa sebagian besar responden berjenis Kelamin perempuan 41 orang $(82 \%)$ dan berusia 17 tahun berjumlah 23 orang (46\%). Usia dan jenis kelamin menurut Tatangelo et al (2015) merupakan salah satu faktor yang mempengaruhi body image .

Usia responden pada penelitian ini adalah usia remaja. Berdasarkan tabel 1 diketahui bahwa responden sebagian besar berusia 17 tahun. Rawana and Morgan (2014) menjelaskan bahwa pada usia 17 tahun merupakan usia puncak pada remaja yang perlu mendapatkan perhatian berkaitan dengan evaluasi body image. Remaja merupakan masa transisi dimana pada usia tersebut remaja mengalami perubahan tubuh akibat dari pertumbuhan dan perkembangan pada masa pubertas. Adanya perubahan selama usia remaja akan mempengaruhi kepuasan terhadap body image (Murray et al, 2011; Lipowski et al, 2016). Pada usia remaja terjadi perubahan yang berkaitan dengan pertumbuhan dan perkembangan fisik dan kognitif. Potter et al (2013) menjelaskan bahwa pertumbuhan dan perkembangan fisik dan kognitif akan mempengaruhi body image. Perubahan perkembangan normal seperti 
pubertas akan mempengaruhi body image dibanding komponen konsep diri yang lain.

\section{b. Jenis Kelamin}

Faktor lain yang mempengaruhi body image adalah jenis kelamin. Berdasarkan Tabel 1 bahwa sebagian besar jenis kelamin responden adalah perempuan. Namun, penurunan body image satisfaction bisa terjadi pada laki - laki maupun perempuan. Masalah yang berkaitan dengan body image pada masa pubertas dapat terjadi pada laki - laki dan perempuan (Tatangelo et al , 2015;Ricciardelli and Yager, 2016, Griff et al,2017).

2. Pengaruh Cognitive Behaviour Therapy (CBT) Terhadap Peningkatan Body Image Satisfaction Pada Remaja

Tabel 2Analisis Bivariat (Paired T Test)

\begin{tabular}{|c|c|c|c|c|}
\hline \multirow[t]{2}{*}{ Kelompok } & \multirow[t]{2}{*}{$\mathbf{N}$} & $\begin{array}{lr}\text { Skor } \quad B \\
\text { Satisfaction } \\
\quad \mathrm{X}\end{array}$ & $y \quad$ Image & \multirow[t]{2}{*}{ p-value } \\
\hline & & Sebelum & Sesudah & \\
\hline $\begin{array}{c}\text { Cognitive } \\
\text { Behaviour Therapy } \\
\text { (CBT) }\end{array}$ & 50 & $93,7 \pm \mathbf{1 0 , 5}$ & $108,74 \pm 9,8$ & 0,000 \\
\hline
\end{tabular}

Berdasarkan Tabel 2 diketahui bahwa remaja memiliki rata - rata body image satisfaction yaitu 93,7 sebelum diberikan Cognitive Behaviour Therapy (CBT) dan sesudah diberikan memiliki rata - rata 108,74 dengan selisih 15,04. Dari hasil analisis data didapatkan bahwa ada perbedaan signifikan antara rata - rata body image satisfaction sebelum dan sesudah diberikan Cognitive Behaviour Therapy (CBT) dimana setelah dilakukan intervensi terjadi peningkatan body image satisfaction. Hal ini sesuai dengan beberapa hasil penelitian yang menjelaskan bahwa Cognitive Behaviour Therapy (CBT) bisa mempengaruhi body image (Wilhelm et al,2011;Controlled and Manzoni, 2015; Harley,2015; Krebs, et al, 2017).

Menurut Krebs et al (2017), tujuan CBT adalah untuk merubah pola pikir negatif menjadi positif sehingga perilaku maladaptif yang timbul akibat pola pikir yang salah juga akan berubah menjadi perilaku yang adaptif sehingga diharapkan individu memiliki kemampuan untuk bereaksi secara adaptif dalam menghadapi masalah atau situasi sulit dalam setiap fase hidupnya. Krebs et al (2017) menyampaikan hal yang sama bahwa fokus dari CBT adalah merubah perilaku melalui distorsi kognitif sehingga terapis membantu remaja untuk mengidentifikasi distorsi kognitif pada remaja yang mengalami masalah dengan body image.

Proses yang terjadi pada pelaksanaan CBT yang terdiri dari 5 sesi adalah membantu individu mengidentifikasi pikiran negatif yang mempengaruhi emosional individu sehingga mengganggu individu (pengkajian), membantu individu untuk belajar mengembangkan kemampuan mencari hal yang positip yang berkaitan dengan individu maupun lingkungan yang ada disekitar individu berdasarkan pada pikiran individu atau melakukan rasionalisasi dan menjadikannya sebagai bahan untuk menolak atau melawan pikiran negatif yang berasal dari individu sendiri (terapi kognitif), menguji dan membantu individu dalam berespon terhadap masalah yang dihadapi (terapi perilaku), meminta klien untuk mendemondtrasikan respon kognitif dan perilaku ketika muncul pikiran negatif dan dukungan serta evaluasi secara terus menerus (Harley, 2015).

Dalam melakukan perlawanan terhadap pikiran negatif diperlukan dorongan yang kuat terutama dari dalam individu sehingga individu mampu merubah pikiran, persepsi, asumsi yang salah yang dipercaya oleh individu yang berpengaruh terhadap emosi individu (Harley, 2015). Kemampuan individu dalam merubah pikiran yang salah dan tidak rasional menjadi pikiran yang positip dan rasional akan mempengaruhi emosi dan perilaku yang menyebabkan remaja mengalami 
peningkatan terhadap body image satisfaction

(Harley,2015; Krebs, et al, 2017).).

\section{KESIMPULAN}

Kesimpulan dalam penelitian ini adalah :

1. Body Image Satisfaction pada remaja sebelum diberikan Cognitive Behaviour Therapy adalah memiliki rata - rata 93,7.

2. Body Image Satisfaction pada remaja sebelum diberikan Cognitive Behaviour Therapy adalah memiliki rata - rata 108,74 .

3. Ada peningkatan Body Image Satisfaction setelah diberikan Cognitive Behaviour Therapy.

Cognitive Behaviour Therapy merupakan salah satu psikoterapi yang efektif dalam meningkatkan body image satisfaction pada remaja sehingga psikoterapi ini bisa diimplementasikan sebagai salah satu upaya untuk mencegah terjadinya perilaku negatif akibat dari persepsi yang salah terhadap body image.

\section{UCAPAN TERIMA KASIH}

Peneliti mengucapkan terima kasih kepada pimpinan STIKes Kepanjen dan seluruh civitas akademika yang senantiasa memberikan dukungan dalam pelaksanaan penelitian, kepala sekolah dan bagian kesiswaan SMK Muhammadiyah 5 Kepanjen yang berkenan sebagai tempat penelitian dan seluruh responden yang telah memberikan waktunya untuk mengikuti kegiatan penelitian.

\section{DAFTAR RUJUKAN}

Andrew, R., Tiggemann, M., \& Clark, L. (2016). Predictors and Health-Related Outcomes of Positive Body Image in Adolescent Girls : A Prospective Study, Developmental Psychology, Vol 52, No 3, March,463-474, http://dx.doi.org/10.1037/dev0000095
Manzoni, Gian Mauro et al. "Virtual RealityEnhanced Cognitive-Behavioral Therapy for Morbid Obesity: A Randomized Controlled Study with 1 Year Follow-Up." Cyberpsychology, behavior and social networking vol. 19, No 2, February,134-40. doi:10.1089/cyber.2015.0208

Gall, K., Zutven, K. Van, Lindstrom, J., Bentley, C., Gratwick-sarll, K., Harrison, C., ... Mond, J. (2016). Obesity and Emotional Well-Being in Adolescents : Roles of Body Dissatisfaction, Loss of Control Eating, and Self-Rated Health, Obesity, Vol 24, No 4, April, 837-842. http://doi.org/10.1002/oby.21428

Grif, S., Ph, D., Murray, S. B., Ph, D., Bentley, C., Psych, D., ... Ph, D. (2017). Sex Differences in Quality of Life Impairment Associated With Body Dissatisfaction in Adolescents. Journal Of Adolescent Health. Vol 61, No 1, July, 77-82, http://doi.org/10.1016/j.jadohealth.2017.01.01 6

Grave, R. D., Calugi, S., Ghoch, M. El, Conti, M., \& Fairburn, C. G. (2014). Inpatient cognitive behavior therapy for adolescents with anorexia nervosa: immediate and longer-term effects, Frontiers in psychiatry, Vol 5, No 14,February, 1-7. http://doi.org/10.3389/fpsyt.2014.00014

Harley, J. (2015). Bridging the Gap between Cognitive Therapy and Acceptance and Commitment Therapy ( ACT ). Procedia Social and Behavioral Sciences, Vol 193, June, 131-140.

http://doi.org/10.1016/j.sbspro.2015.03.252

Jarry, L., \& Ip, K. (2005). The effectiveness of standalone cognitive-behavioural therapy for body image : A meta-analysis, Body Image, Vol 2, No 4,December, 317-331. http://doi.org/10.1016/j.bodyim.2005.10.001 
Jones, D. C., \& Smolak, L. (2011). Body Image during Adolescence: A Developmental Perspective. Encyclopedia of Adolescence, Elsevier Inc. http://doi.org/10.1016/B978-0-12-3739513.00005-3

Krebs, G., Monzani, B., Bowyer, L., Anson, M., Cadman, J., Heyman, I., ... Mataix-cols, D. (2017). ScienceDirect Long-Term Outcomes of Cognitive-Behavioral Therapy for Adolescent Body Dysmorphic Disorder. Behavior Therapy, Vol 48, No 4, 462-473. http://doi.org/10.1016/j.beth.2017.01.001

Latiff, A. A., Um, M., Muhamad, J., Fam, M., Usm, M., Rahman, R. A., ... Usm, M. (2018). Body image dissatisfaction and its determinants among young primary-school adolescents. Journal of Taibah University Medical Sciences, Vol 13, No 1, 34-41. http://doi.org/10.1016/j.jtumed.2017.07.003

Lipowski, M., Olszewski, H., \& Dykalska-bieck, D. (2016). Gender differences in body-esteem among seniors: Beauty and health considerations, Archives of gerontology and geriatrics Vol 67, November-December 160170.

http://doi.org/10.1016/j.archger.2016.08.006

Marco, H., \& Perpin, C. (2013). Effectiveness of cognitive behavioral therapy supported by virtual reality in the treatment of body image in eating disorders: One year follow-up, Psychiatry Research, Vol 209 No 3, October, 619-625.

http://doi.org/10.1016/j.psychres.2013.02.023

Mataix-cols, D., Fernández, L., Cruz, D., Isomura, K., Anson, M., Turner, C., ... Krebs, G. (2015). A Pilot Randomized Controlled Trial of Cognitive-Behavioral Therapy for Adolescents With Body Dysmorphic Disorder. Journal of the American Academy of Child \& Adolescent
Psychiatry, Vol 54, No 11, November, 895904,http://doi.org/10.1016/j.jaac.2015.08.011

Murray, K. M., Byrne, D. G., \& Rieger, E. (2011). Investigating adolescent stress and body image. Journal of Adolescence, Vol 34, No 2, April, 269-278.

http://doi.org/10.1016/j.adolescence.2010.05.0 04

Talen, M. R., \& Mann, M. M. (2009). Obesity and Mental Health, Vol 36, 287-305. http://doi.org/10.1016/j.pop.2009.01.012

Tatangelo, G. L., Mccabe, M. P., \& Ricciardelli, L. A. (2015). Body Image. International Encyclopedia of Social \& Behavioral Sciences (Second Edition, Vol. 2). Elsevier. http://doi.org/10.1016/B978-0-08-097086-

8.14062-0

Timko, C. A., Juarascio, A. S., Martin, L. M., Faherty, A., \& Kalodner, C. (2014). An under-explored yet important factor in the relationship between body image dissatisfaction and disordered eating. Journal of Contextual Behavioral Science, Vol 3, No 3, July, 1-9. http://doi.org/10.1016/j.jcbs.2014.01.002

Wichstrøm, L., \& Soest, T. Von. (2016). Reciprocal relations between body satisfaction and selfesteem : A large 13-year prospective study of adolescents. Journal of Adolescence, Vol 47, No 7491, February,16-27. http://doi.org/10.1016/j.adolescence.2015.12.0 03

Yang, H., Yang, Y., Xu, L., Wu, Q., Xu, J., Weng, E., .. Cai, S. (2017). The relation of physical appearance perfectionism with body dissatisfaction among school students $9-18$ years of age. Personality and Individual Differences, 116, October, 399-404. http://doi.org/10.1016/j.paid.2017.05.005 
Wilhelm, S., Phillips, K. A., Fama, J. M., Greenberg, J. L., \& Steketee, G. (2011). Modular Cognitive - Behavioral Therapy for Body Dysmorphic Disorder. Behavior Therapy, Vol 42, No 4,
624-633, May,

http://doi.org/10.1016/j.beth.2011.02.002

Cite this article as: Agustiningsih N, Fanani Q ( (2019). Pengaruh Cognitive Behaviour Therapy (CBT) Terhadap Peningkatan Body Image Satisfaction Pada Remaja

Jurnal Ilmiah Media Husada. Vol. 8 No.2, halaman awal-halaman akhir. https://doi.org/10.33475/jikmh.v8i2.20 